\section{Association of leptin levels with pathogenetic risk of coronary heart disease and stroke: a meta-analysis}

\author{
Associação entre as concentrações de leptina e o \\ risco patogenético de doença arterial coronariana \\ e acidente vascular cerebral: uma metanálise
}

Rui Zeng', Chun-Hua Xu², Yuan-Ning Xu', Ya-li Wang', Mian Wang'

\begin{abstract}
Objective: This meta-analysis aimed to investigate the association of leptin levels with pathogenetic risk of CHD and stroke. Materials and methods: Studies were identified in the PubMed, Embase, and Springer link database without language restriction. Odds ratios (ORs) and corresponding $95 \%$ confidence intervals ( $95 \% \mathrm{Cls}$ ) were used as effect indexes. The association of leptin levels with pathogenetic risk of $\mathrm{CHD}$ and stroke, as well as the risk variation of $\mathrm{CHD}$ with each additional one unit of leptin level were examined via meta-analysis. The publication bias was assessed via Egger's linear regression test. Results: Eight nested case-control studies consisting of 1,980 patients and 11,567 controls were included for current meta-analysis. ORs (95\% Cls) of association of leptin levels with CHD and stroke was $1.90(1.06,3.43)$, and $2.14(1.48,3.08)$, respectively. In addition, significant result was obtained regarding the risk variation of CHD with each additional one unit of leptin level $(\mathrm{OR}=1.04,95 \% \mathrm{Cl}=1.00-1.08, P=0.044)$. There was no significant publication bias as suggested by Egger test outcomes. Conclusion: There was a significant association of leptin with pathogenetic risk of CHD and stroke, and raised leptin levels could significantly increase the pathogenetic risk of CHD. Arq Bras Endocrinol Metab. 2014;58(8):817-23
\end{abstract}

Keywords

Leptin; coronary heart disease; stroke; meta-analysis

\section{RESUMO}

Objetivo: O objetivo desta metanálise foi investigar a associação entre os níveis de leptina e o risco patogenético de doença arterial coronariana e acidente vascular cerebral. Materiais e métodos: Foram identificados estudos nas bases de dados PubMed, Embase e Springer Link sem restrição quanto à língua. A razão de chances (OR) e os intervalos de confiança de $95 \%$ correspondentes ( $95 \% \mathrm{Cl}$ ) foram usados como índices de efeitos. A associação entre os níveis de leptina e o risco patogenético de doença arterial coronariana e acidente vascular cerebral com cada unidade adicional na concentração de leptina foi analisada por meio de metanálise. $O$ viés da publicação foi avaliado por meio do teste de regressão linear de Egger. Resultados: Oito estudos com caso controle aninhado envolvendo 1.980 pacientes e 11.567 controles foram incluídos na metanálise. As ORs (95\% Cls) da associação entre as concentrações de leptina e a doença arterial coronariana e o acidente vascular cerebral foram de $1,90(1,06 ; 3,43)$ e $2,14(1,48 ; 3,08)$, respectivamente. Além disso, foram obtidos resultados significativos com a variação de risco para a doença arterial coronariana a cada unidade adicional na concentração de leptina ( $\mathrm{OR}=1,04 ; 95 \% \mathrm{Cl}=1,00-1,08 ; P=0,044)$. Não houve viés de publicação significativo sugerido pelos desfechos no teste de Egger. Conclusão: Há associação significativa entre a leptina e o risco patogenético de doença arterial coronariana e acidente vascular cerebral, e concentrações aumentadas de leptina podem elevar significativamente o risco patogenético de doença arterial coronariana. Arq Bras Endocrinol Metab. 2014;58(8):817-23

Descritores

Leptina; doença arterial coronariana; acidente vascular cerebral; metanálise
1 Department of Cardiovascular Diseases, West China Hospital, School of Clinical Medicine, Sichuan University, Chengdu, China ${ }^{2}$ Department of Cardiovascular Diseases, the second people's Hospital of Neijiang, Neijiang, China Rui Zeng and Chun-Hua Xu are regarded as co-first author

\section{Correspondence to: Mian Wang Department of Cardiovascular Diseases, West China Hospital, School of Clinical Medicine, Sichuan University, 37 610041 - Guoxuexiang, Chengdu China \\ mianwwang@hotmail.com}

Received on Apr/1/2014 Accepted on July/8/2014

DOI: 10.1590/0004-2730000003390 


\section{INTRODUCTION}

C ardiovascular disease (CVD), particularly coronary heart disease (CHD) and stroke remains the biggest cause of death worldwide (1). A number of proven and putative risk markers contributing to CVD have been identified, involving smoking, elevated glucose, hypertension, hyperlipidaemia, obesity, and markers of infection or inflammation and lifestyle (poor nutrition and lack of exercise) (2). Among these risk markers, obesity has been shown to be highly associated with CVD (3), and the underlying mechanism has been fully depicted (4). Furthermore, insulin resistance was found to be implicated with several of the possible mechanisms linking obesity to CVD, and the adipocyte-derived hormone leptin has been suggested to be associated with insulin resistance and thus may play an important role in linking obesity to CVD $(5,6)$.

Leptin, peptide product of adipose tissue specific obese (ob) gene, was discovered in 1994 (7) with significant role in the regulation of energy homeostasis, neuroendocrine function, and metabolism. Understandably, the finding about its association with insulin resistance, metabolic disturbances and cardiovascular risk subsequently sparked much interest focused on the relationship between the leptin and CVD (8-12).

Regarding this relationship, however, contradictory results were obtained. A large prospective study was conducted to examine the association of leptin levels with the risk of CHD indicating that leptin was a novel, independent risk factor for CHD (13), similarly, another investigation concluded that high leptin level was significantly associated with myocardial infarction as well as stroke in men and women, independently of several cardiovascular risk factors and obese status (14). Additionally, significant association of leptin levels with risk of CHD and stroke were also demonstrated by other studies focused on these relationships (15-18). On the other hand, in contrast to those fairly strong associations previously reported, a recent prospective study and systematic review have found that a moderate association was existed between leptin levels and CHD risk, but no statistically significant association was observed after adjustment for body mass index (BMI) (9) which is consistent with another report from populationbased case-cohort study (12). In addition, more recent study focused on these associations revealed that leptin was not associated with incident CHD or incident stroke (19).

To provide reliable evidence and help clarify matters behind this controversy, we conducted current metaanalysis study to examine the association of leptin levels with risk of CHD and stroke, as well as the risk variation of CHD with each additional one unit of leptin level.

\section{MATERIALS AND METHODS}

\section{Search strategy}

Up to $27^{\text {th }}$ December 2013 , studies were identified in the PubMed, Embase, and Springer link database without language restriction, using the words "adipokines or adipocytokines or leptin" and "coronary heart disease (CHD) or coronary artery disease (CAD) or myocardial infarction or stroke". In addition, we searched the paper version publications by manual retrieval, and any additional studies in the reference lists of related reviews or included literatures were also screened to obtain more eligible studies for our meta-analysis.

\section{Inclusion and exclusion criteria}

We adopted the following inclusion criteria: (a) a casecontrol study or cohort study based on CHD or stroke patients as subjects and healthy population as the control group; (b) association of leptin with pathogenetic risk of CHD or stroke were assessed; (c) odds ratios (ORs) or risk ratios (RRs) and their $95 \%$ confidence intervals (95\% CIs) were used as effect evaluation index. On the other hand, study was excluded if CHD or stroke patients were involved in baseline population; all relevant review, report, review literature, letters were also excluded; and all studies were excluded except the one offering more study information when the study was duplicate publication or used the data from same population.

\section{Data extraction and statistical analysis}

Two investigators independently extracted the information that involved the first author, year of publication, geographic area, age and gender of participant, sample volume, amount of cases, types of outcomes, ORs/RRs and $95 \%$ CIs after adjustment, and the correction factors. Additionally, any disagreements were resolved via discussion with the third investigator. 
ORs and 95\% CIs were used as effect indexes in present study assessing the association of leptin with pathogenetic risk of $\mathrm{CHD}$ or stroke. The heterogeneity among studies was determined by the $\mathrm{X}^{2}$-test based Q-statistic (20), the random-effects model meta-analysis was applied for heterogeneous outcomes $\left(P<0.05, \mathrm{I}^{2}>50 \%\right)$, and the fixed-effect model meta-analysis was used for homogeneous outcomes $\left(P \geq 0.05, \mathrm{I}^{2} \leq 50 \%\right)$. The publication bias was assessed via Egger test (21). Data analysis was performed with the Stata 11.0 Software.

\section{RESULTS}

\section{Eligible studies}

Initially, a total of 3,099 preliminary related articles were obtained from the electronic database, subsequently 1,899 articles were reserved after eliminating duplicate documents, and then 1,870 articles were further excluded according to the inclusion criteria after scanning the titles and abstracts. Moreover, scrutiny of the full text led to the exclusion of 21 articles. Additionally, none articles were obtained from manual retrieval, as a result, a total of 8 articles (13-17,22-24) were identified for current meta-analysis. The detailed process of literature search and study selection is explicitly described in figure 1 .

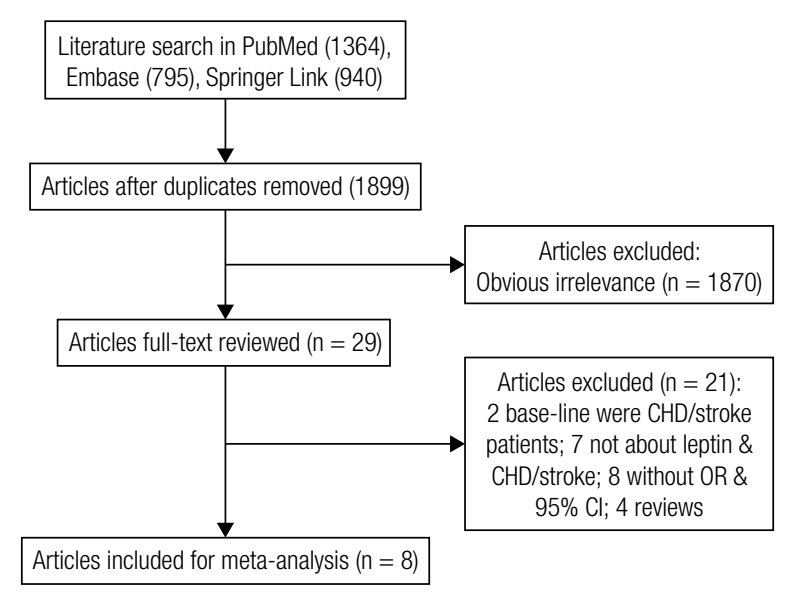

Figure 1. Literature search and study selection.

\section{Study characteristics}

As shown in table 1, eight nested case-control studies consisting of 1,980 patients and 11,567 controls were included for current meta-analysis. All participants were adults with age from 20 to 89 years. These studies, published during 1999 to 2010 , were conducted in three different areas involved five from Europe, two from U.S.A., and one from India. The leptin levels were treated with logarithmic transformation. Performing the association analysis of leptin levels with CHD or stroke, three studies treated leptin levels as continuity data to assess the risk variation for CHD with each

Table 1. Characteristics of 8 studies on leptin and risk of $\mathrm{CHD} / \mathrm{Stroke}$

\begin{tabular}{|c|c|c|c|c|c|c|c|}
\hline Study reference & Year & Location & Age & $\mathbf{n}$ & $\begin{array}{c}\text { Type of } \\
\text { outcome }\end{array}$ & Case & $\mathbf{O R}$ \\
\hline Soderberg & 1999 & Sweden & $25-74$ & $186 \mathrm{M} \& \mathrm{~F}$ & Ml & 62 & $\begin{array}{c}8.97(1.73,46.5) \\
1.14(1.04,1.25)\end{array}$ \\
\hline Wallace & 2001 & Scotland & $56^{*}$ & $1,160 \mathrm{M}$ & CHD & 377 & $1.70(1.05,2.76)$ \\
\hline Soderberg & 2003 & Sweden & $72^{*}$ & $\begin{array}{l}112 \mathrm{~F} \\
126 \mathrm{M}\end{array}$ & IS & $\begin{array}{l}74 \\
63\end{array}$ & $\begin{array}{l}4.10(1.45,11.62) \\
4.89(1.89,12.62)\end{array}$ \\
\hline Wallerstedt & 2004 & $\begin{array}{l}\text { Sweden }+ \\
\text { Finland }\end{array}$ & $57(6.6)$ & $\begin{array}{l}133 \mathrm{~F} \\
380 \mathrm{M}\end{array}$ & Ml & $\begin{array}{c}45 \\
126\end{array}$ & $\begin{array}{l}1.02(1.00,1.04) \\
1.01(1.00,1.02)\end{array}$ \\
\hline Jose & 2005 & India & $52^{*}$ & $140 \mathrm{~F} \& \mathrm{M}$ & Ml & 94 & $1.48(1.19,1.85)$ \\
\hline Lawlor & 2007 & UK & $60-79$ & $500 \mathrm{~F}$ & CHD & 165 & $1.00(0.80,1.26)$ \\
\hline Sierra-Johnson & 2007 & USA & $20-89$ & $\begin{array}{l}3,336 \mathrm{~F} \\
2,903 \mathrm{M}\end{array}$ & $\begin{array}{l}\text { Stroke } \\
\text { Ml } \\
\text { Stroke } \\
\text { Ml }\end{array}$ & $\begin{array}{c}78 \\
74 \\
82 \\
154\end{array}$ & $\begin{array}{c}3.20(1.04,10.54) \\
3.96(1.29,12.72) \\
1.37(0.48,3.88) \\
3.16(1.40,7.37)\end{array}$ \\
\hline Liu & 2010 & USA & $21-84$ & $\begin{array}{c}2,928 \mathrm{~F} \\
1,643 \\
M\end{array}$ & $\begin{array}{l}\text { Stroke } \\
\text { CHD } \\
\text { Stroke } \\
\text { CHD }\end{array}$ & $\begin{array}{c}132 \\
191 \\
93 \\
170\end{array}$ & $\begin{array}{l}1.97(1.21,3.21) \\
0.96(0.66,1.39) \\
1.70(0.51,5.68) \\
0.72(0.23,2.23)\end{array}$ \\
\hline
\end{tabular}

M: male; F: female; MI: myocardial infarction; CHD: coronary heart disease; IS: ischemic stroke. *: mean age. 
additional one unit, while two or three categories of leptin levels were used in four studies to evaluate the risk differences of $\mathrm{CHD}$ or stroke under high and low levels, and the mentioned two kinds of results were included in the rest one study.

\section{Correlation analyses between leptin and CHD or stroke}

According to the characteristics of included studies, the mentioned two kinds of assessments were performed with quantitative analysis regarding the ORs and their 95\% CIs. Significant association was observed for leptin levels with pathogenetic risk of $\mathrm{CHD}(\mathrm{OR}=1.90,95 \%$
$\mathrm{CI}=1.06-3.43, P=0.032)$, and the random-effects model was conducted with corresponding heterogeneous outcome $\left(P=0.004, \mathrm{I}^{2}=71.5 \%\right.$, Figure $\left.2 \mathrm{~A}\right)$; similarly, a significant association was also existed between leptin levels with pathogenetic risk of stroke $(\mathrm{OR}=2.14,95 \% \mathrm{CI}=1.48-3.08, P<0.001)$, and the fixed-effects model was applied for its homogeneous outcome $\left(P=0.572, \mathrm{I}^{2}=0.0 \%\right.$, Figure $\left.2 \mathrm{~B}\right)$. The result regarding the risk variation for $\mathrm{CHD}$ with each additional one unit of leptin level was $(\mathrm{OR}=1.04,95 \% \mathrm{CI}$ $=1.00-1.08, P=0.044)$, and the random-effects model was conducted with corresponding heterogeneous outcome $\left(P=0.001, I^{2}=78.4 \%\right.$, Figure 3$)$.

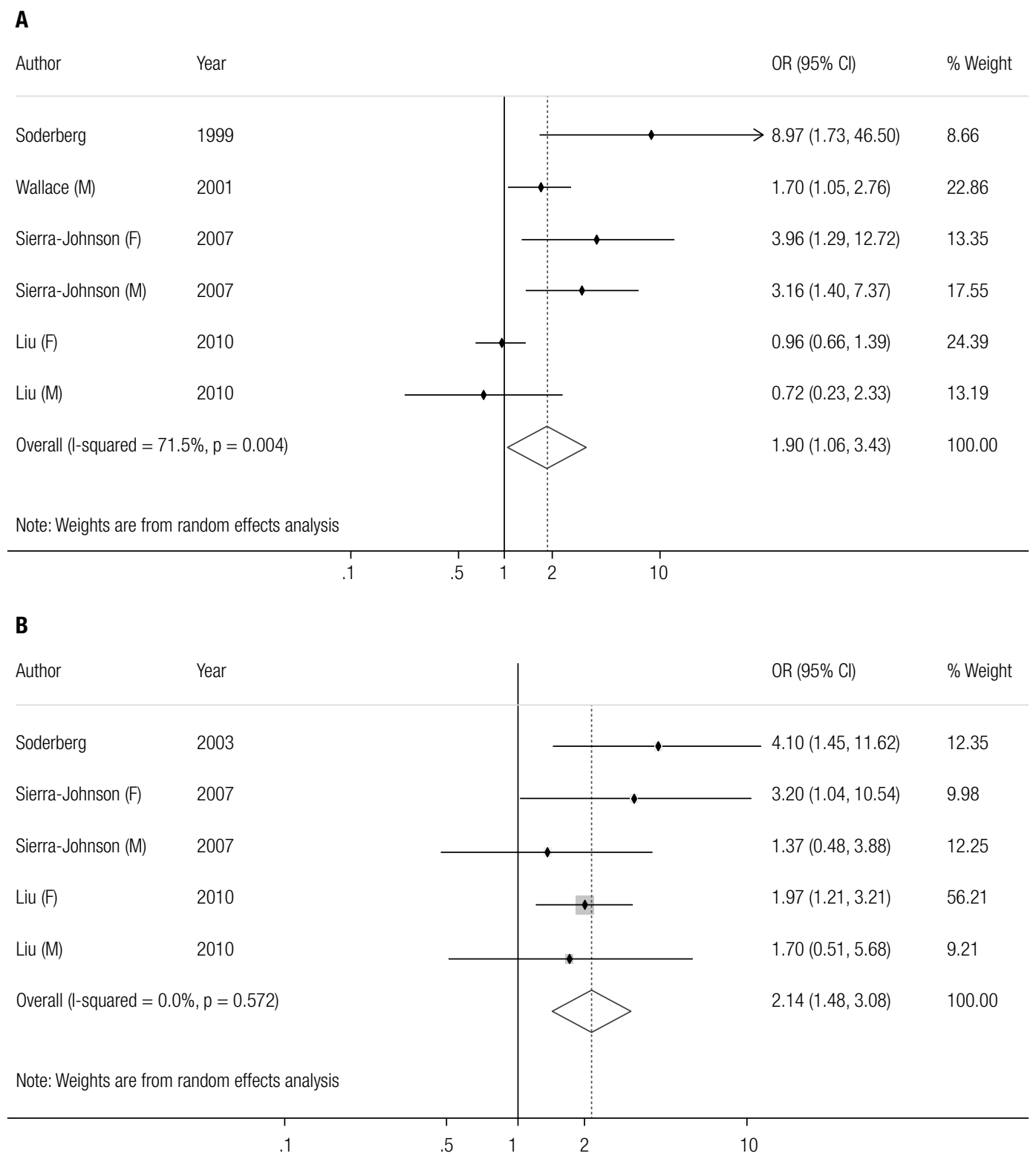

Figure 2. Pooled analyses of risk difference between diverse leptin levels with $\mathrm{CHD}(\mathbf{A})$ and with stroke (B). 


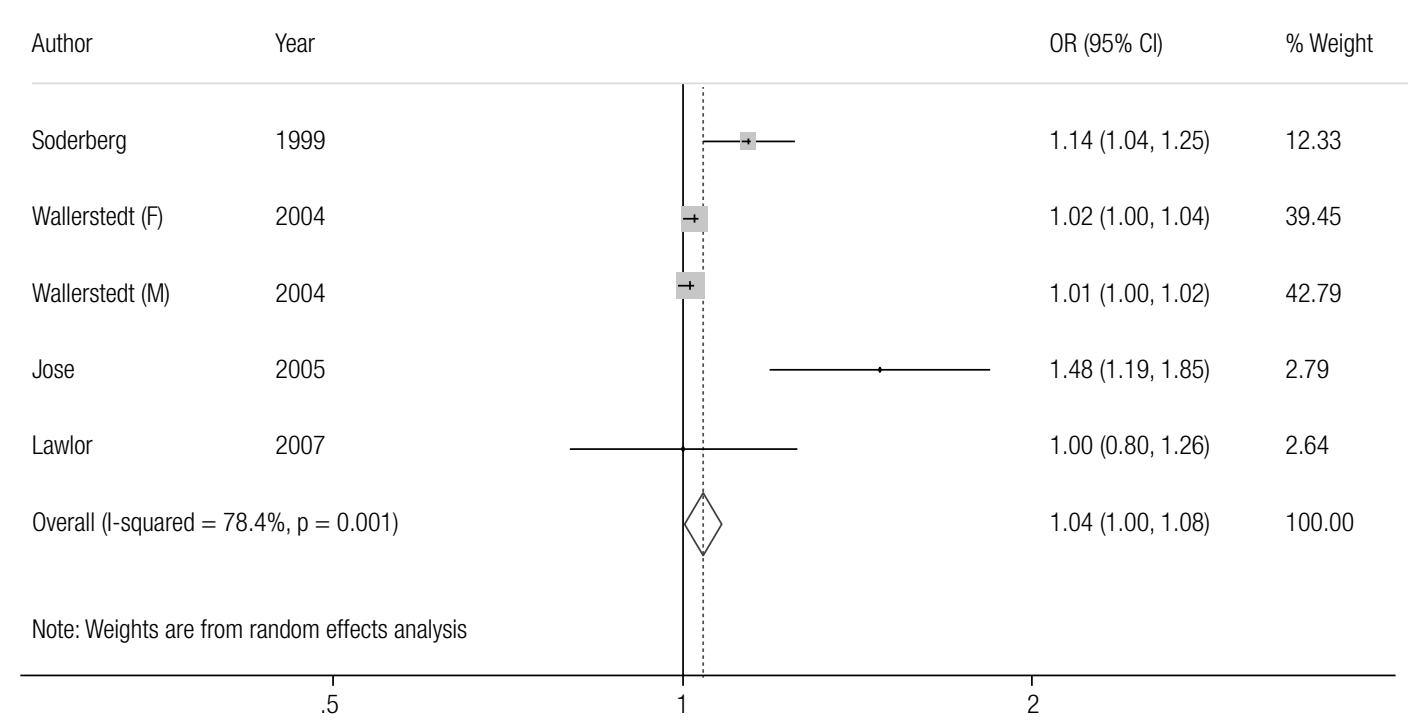

Figure 3. Pooled analyses of risk variation for $\mathrm{CHD}$ with each additional one unit of leptin level.

\section{Publication bias}

According to the studies depicted in figure $2 \mathrm{~A}, \mathrm{~B}$ and figure 3 , there was no significant publication bias as suggested by Egger test outcomes $(P=0.665$, $P=0.141, P=0.108$, respectively).

\section{DISCUSSION}

A total of 8 nested case-control studies consisting of 1,980 patients and 11,567 controls were subjected to present meta-analysis. A significant association of leptin levels with incident CHD and stroke was identified, in addition, the CHD risk increased by $4 \%$ with each additional one unit of leptin level. The results are aligned with the earlier studies conducted by Söderberg and his group $(10,15,16,25,26)$.

Initially, they demonstrated elevated plasma leptin level was an independent predictor of first-ever hemorrhagic stroke but not ischemic. In addition, they proposed that the possible mechanism regarding this association may involve the effect of leptin on sympathetic nervous system activation and BP, lipid levels, as well as the fibrinolytic system Whereas, their later larger case-referent study (16) showed that leptin was associated with both ischemic and hemorrhagic stroke in men and women. It is noteworthy that the different results of these studies may be owing to the limited cases included for the former one. Furthermore, their further research (26) indicated that leptin was an independent predictor of stroke in men, even after adjustment for traditional stroke risk factors. This result is consistent with a recent report (18) that leptin was associated with incident stroke after adjusting for BMI and established risk factors for stroke. This report also contains a suggestion that direct atherogenic effect of leptin on the carotid artery wall may be the pathway for development of stroke. The mechanism of this association was not well understood currently, and similar possible mechanism suggested by these studies mainly involved the atherothrombotic process, which is associated with hyperleptinemia.

Regarding the relationship between leptin and incident CHD, mixed results of previous studies seems to be difficult to explain. It was reported (27) that leptin did not display as a significant predictor for ischemic heart disease with the samples matched for potential risk markers such as smoking and BMI. However, subsequent nested case-referent study by Söderberg and cols. revealed that leptin was an independent risk factor for acute myocardial infarction even after adjustment of several cardiovascular risk factors, such as high BMI, blood pressure and hyperinsulinaemia (15). Meanwhile, a later cross-sectional study also demonstrated that serum leptin was a significant determinant of CAD in addition to other established cardiovascular risk factors, such as smoking, age, gender, fasting insulin and BMI, and the capacity of leptin activating the sympathetic nervous system was considered as pivotal role for the significant association (28). Notably, discrepant results observed from these and subsequent studies mainly attributed to different study design, particularly the different treatment for various cardiovascular risk factors. In current meta-analysis, the confounders such 
as age, blood pressure, and BMI have been adjusted in all included studies. Nevertheless, the results may be influenced by some potential confounders, consequently, further research should be perform to obtain more potent evidence regarding this relationship with exploring the mechanism and effect magnitude.

To our knowledge, the present study is the first meta-analysis focused on the association of leptin levels with pathogenetic risk of $\mathrm{CHD}$ and stroke as well as the risk variation for $\mathrm{CHD}$ with each additional one unit of leptin level. Although there were some differences towards grouping criteria among these included studies, the results were still strengthened by the observation that CHD risk was significantly increased with each additional one unit of leptin level. Furthermore, there was no significant publication bias between studies. On the other hand, potential limitations of present study merit careful consideration. We only obtained observational studies for this study. These results may be influenced by some potential confounders, which may lead to the exaggeration of the positive effect of leptin on CHD and stroke, although the confounders such as age, blood pressure, and BMI have been adjusted in all these 8 studies; on another aspect, eligible studies included for this meta-analysis was limited and the sample sizes particularly the cases amount was inadequate, therefore further meta-analysis with larger sample sizes and comprehensive study design is warranted to confirm the results stability of current study.

In conclusion, a significant association of leptin levels with incident CHD and stroke was demonstrated, and raised leptin levels could significantly increase the pathogenetic risk of CHD. However, further metaanalysis involving larger sample sizes with analysis of sub-groups by age or gender is warranted for more detailed evidence.

Disclosure: no potential conflict of interest relevant to this article was reported.

\section{REFERENCES}

1. Sheet-Populations SF. International cardiovascular disease statistics. American Heart Association. 2004.

2. Yusuf S, Reddy S, Ôunpuu S, Anand S. Global burden of cardiovascular diseases part I: general considerations, the epidemiologic transition, risk factors, and impact of urbanization. Circulation. 2001;104(22):2746-53.

3. Silva M, Laet C, Nusselder WJ, Mamun AA, Peeters A. Adult obesity and number of years lived with and without cardiovascular disease. Obesity. 2006;14(7):1264-73.
4. Van Gaal LF, Mertens IL, Christophe E. Mechanisms linking obesity with cardiovascular disease. Nature. 2006;444(7121):875-80.

5. Patel SB, Reams GP, Spear RM, Freeman RH, Villarreal D. Leptin: linking obesity, the metabolic syndrome, and cardiovascular disease. Curr Hypertens Rep. 2008;10(2):131-7.

6. Zimmet P, Collins V, De Courten M, Hodge A, Collier G, Dowse G, et al. Is there a relationship between leptin and insulin sensitivity independent of obesity? A population-based study in the Indian Ocean nation of Mauritius. Mauritius NCD Study Group. Int J Obes Relat Metab Disord. 1998;22(2):171-7.

7. Zhang $Y$, Proenca R, Maffei M, Barone M, Leopold L, Friedman JM. Positional cloning of the mouse obese gene and its human homologue. Nature. 1994;372(6505):425-32.

8. Ashwin PJ, Dilipbhai PJ. Leptin and the cardiovascular system: a review. Recent Pat Cardiovasc Drug Discov. 2007;2(2):100-9.

9. Sattar N, Wannamethee G, Sarwar N, Chernova J, Lawlor DA, Kelly $A$, et al. Leptin and coronary heart disease: prospective study and systematic review. J Am Coll Cardiol. 2009;53(2):167-75.

10. Söderberg S, Colquhoun D, Keech A, Yallop J, Barnes E, Pollicino $C$, et al. Leptin, but not adiponectin, is a predictor of recurrent cardiovascular events in men: results from the LIPID study. Int $J$ Obes (Lond). 2009;33(1):123-30.

11. Lieb W, Sullivan LM, HarrisTB, Roubenoff R, Benjamin EJ, Levy D, et al. Plasma leptin levels and incidence of heart failure, cardiovascular disease, and total mortality in elderly individuals. Diabetes Care. 2009;32(4):612-6.

12. Karakas M, Zierer A, Herder C, Baumert J, Meisinger C, Koenig $W$, et al. Leptin, adiponectin, their ratio and risk of coronary heart disease: results from the MONICA/KORA Augsburg Study 19842002. Atherosclerosis. 2010;209(1):220-5.

13. Wallace AM, McMahon AD, Packard CJ, Kelly A, Shepherd J, Gaw $A$, et al. Plasma leptin and the risk of cardiovascular disease in the west of Scotland coronary prevention study (WOSCOPS). Circulation. 2001;104(25):3052-6.

14. Sierra-Johnson J, Romero-Corral A, Lopez-Jimenez F, Gami AS, Sert Kuniyoshi FH, Wolk R, et al. Relation of increased leptin concentrations to history of myocardial infarction and stroke in the United States population. Am J Cardiol. 2007;100(2):234-9.

15. Söderberg S, Ahren B, Jansson JH, Johnson O, Hallmans G, Asplund $\mathrm{K}$, et al. Leptin is associated with increased risk of myocardial infarction. J Intern Med. 1999;246(4):409-18.

16. Söderberg S, Stegmayr B, Ahlbeck-Glader C, Slunga-Birgander L, Ahren B, Olsson T. High leptin levels are associated with stroke. Cerebrovasc Dis. 2003;15(1-2):63-9.

17. Wallerstedt SM, Eriksson A-L, Niklason A, Ohlsson C, Hedner T. Serum leptin and myocardial infarction in hypertension. Blood Press. 2004;13(4):243-6.

18. Wannamethee SG, Shaper AG, Whincup PH, Lennon L, Sattar N. Adiposity, adipokines, and risk of incident stroke in older men. Stroke. 2013;44(1):3-8.

19. Bidulescu A, Liu J, Chen Z, Hickson DA, Musani SK, Samdarshi $T E$, et al. Associations of adiponectin and leptin with incident coronary heart disease and ischemic stroke in African Americans: the Jackson Heart Study. Front Public Health. 2013;1:16.

20. Higgins JP, Thompson SG, Deeks JJ, Altman DG. Measuring inconsistency in meta-analyses. BMJ. 2003;327(7414):557.

21. Egger $M$, Smith GD, Schneider M, Minder C. Bias in meta-analysis detected by a simple, graphical test. BMJ. 1997;315(7109):629-34.

22. Liu J, Butler KR, Buxbaum SG, Sung JH, Campbell BW, Taylor HA. Leptinemia and its association with stroke and coronary heart disease in the Jackson Heart Study. Clin Endocrinol (Oxf). 2010;72(1):32-7.

23. Lawlor DA, Smith GD, Kelly A, Sattar N, Ebrahim S. Leptin and coronary heart disease risk: prospective case control study of British women. Obesity. 2007;15(7):1694-701. 
24. Jose VJ, Mariappan P, George PV, Selvakumar D. Serum leptin levels in acute myocardial infarction. Indian Heart $\mathrm{J}$. 2005;57(1):39.

25. Söderberg $S$, Ahrén B, Stegmayr B, Johnson O, Wiklund P-G, Weinehall $L$, et al. Leptin is a risk marker for first-ever hemorrhagic stroke in a population-based cohort. Stroke. 1999;30(2):328-37.

26. Söderberg S, Stegmayr B, Stenlund H, Sjöström LG, Ågren Å, Johansson $L$, et al. Leptin, but not adiponectin, predicts stroke in males. J Intern Med. 2004;256(2):128-36.
27. Couillard $C$, Lamarche $B$, Mauriège $P$, Cantin $B$, Dagenais GR, Moorjani $S$, et al. Leptinemia is not a risk factor for ischemic heart disease in men: prospective results from the Quebec Cardiovascular Study. Diabetes Care. 1998;21(5):782-6.

28. Stangl K, Cascorbi I, Laule M, Stangl V, Vogt M, Ziemer S, et al. Elevated serum leptin in patients with coronary artery disease: no association with the Trp64Arg polymorphism of the beta3-adrenergic receptor. Int $\mathrm{J}$ Obes Relat Metab Disord. 2000;24(3):369-75. 